\title{
La estabilidad en pequeñas cooperativas de la Ciudad de México. Un análisis desde la modernidad sólida y la Economía Social y Solidaria
}

\section{Gerardo Luvián-Reyes, Mara Rosas-Baños}

RESUMEN: El Estado del Bienestar (modernidad sólida) moldeó la lógica de los sujetos con base en las condiciones estructurales de estabilidad laboral de largo plazo que favorecieron los lazos sociales. Contrario a esto, el modelo neoliberal (modernidad líquida) impulsó el individualismo, incrementó la incertidumbre laboral y el desempleo, situación que originó la expansión de la Economía Social y Solidaria en la que una de sus principales formas de organización es el cooperativismo. El objetivo del artículo es analizar la gestión y condiciones laborales de los socios de pequeñas cooperativas familiares de la Ciudad de México, a partir de su cercanía o alejamiento a las características del trabajo en la modernidad líquida, sólida y la Economía Social y Solidaria, para conocer las características del trabajo que se presenta en las cooperativas. Las preguntas que se contestan en este artículo son: ¿Las condiciones laborales que se presentan en el Estado del Bienestar son iguales a las que se propone alcanzar la Economía Social y Solidaria? y siendo dos marcos teóricos distintos ¿Cuáles entonces son las particularidades del trabajo en la Economía Social y Solidaria? Para ello se seleccionaron ocho casos a través del análisis discriminante, considerando viabilidad económica y apropiada gestión cooperativa. Las entrevistas semiestructuradas realizadas fueron analizadas con el software Atlas ti.8. Se concluye que los socios de las cooperativas no sólo buscan la estabilidad laboral, sino que presentan características del trabajo emancipado exclusivas de la Economía Social y Solidaria.

PALABRAS CLAVE: Modernidad líquida, modernidad sólida, cooperativismo, Economía Social y Solidaria, incertidumbre laboral, estabilidad laboral, trabajo.

CLAVES ECONLIT: Z130, E703, D710.

Cómo citar este artículo/How to cite this article: LUVIÁN-REYES, G. \& ROSAS-BAÑOS, M. (2021): "La estabilidad en pequeñas cooperativas de la Ciudad de México. Un análisis desde la modernidad sólida y la Economía Social y Solidaria", CIRIEC-España, Revista de Economía Pública, Social y Cooperativa, 102, 229-258. DOI: 10.7203/CIRIEC-E.102.18394.

Correspondencia: Gerardo Luvián Reyes, Consultor Independiente de Economía Solidaria en la Secretaría del Trabajo y Fomento al Empleo de la Ciudad de México, gerardo.luvian.reyes@gmail.com, ORCID: 0000-00022387-8161; Mara Rosas Baños, Instituto Politécnico Nacional, Centro de Investigaciones Económicas, Administrativas y Sociales, mrosasb@ipn.mx, 0RCID: 0000-0001-7770-4426. 


\section{Expanded abstract}

\section{Stability in small cooperatives in Mexico City. An analysis from the perspective of solid modernity and the Social and Solidarity Economy}

The Social and Solidarity Economy in the urban environment of Mexico City was expanded from the conditions of unemployment and labor precariousness generated by liquid modernity from its beginnings. The search for labor stability necessarily takes us back to the times of the Welfare State, which contributed to the construction of a sense of community in the urban environment. The objective of this research was to analyze proximity or distance to the characteristics of work in the liquid and solid modernity and the Social and Solidarity Economy of small family cooperatives in Mexico City. The questions to be answered in this article are: Are the working conditions that were present in the Welfare State the same as those proposed to be achieved by the Social and Solidarity Economy? And, being two different theoretical frameworks, what then are the particularities of work in the Social and Solidarity Economy?

The research methodology was mixed, quantitative for the selection of cooperatives that met two requirements: appropriate cooperative management and economic viability, this was done through a discriminant analysis, a multivariate statistical technique. The database used to perform the discriminations was that of the 2015 "Economic Diagnosis on Cooperativism of the Federal District", with 192 cooperatives representative at 90\% confidence of 1,589. The methodology was developed in detail in Luvián, Rosas, and Ramírez (2019) from the crossings resulted in 22 cooperatives with the economic viability and 130 with appropriate cooperative management, from which 12 cooperatives were reached that met both criteria. However, for reasons of accessibility, only eight could be interviewed. The qualitative methodology considered the theoretical approach to determine the categories of analysis and thematic axes of the interviews: capital-labor, space-time, and community and individual. The principles for internal management were taken from cooperativism: democratic control, democratic participation, and autonomy and independence; with emphasis on democracy through the organization chart (General Assembly, Board of Directors, and Supervisory Board). The interviews were applied to the legal representatives of the cooperatives. The responses were analyzed employing the categorization method to process the text of the interviews through categories and subcategories and thus present through words or short phrases the similarities and differences of the interviewees through the themes and components of the topic. The categories were organized through networks with the Atlas ti.8 software, examining mainly aspects such as the basis and density of the networks with the co-occurrence method. 
The results show that cooperatives present stability conditions like those existing in solid modernity such as: maintaining the equivalent of a fixed salary, having a stable workplace, fixed working hours, and forming a social welfare fund. However, there are fundamental differences in the way these conditions of stability are achieved in the Social and Solidarity Economy, which have to do with the organization of work within cooperatives. The main difference between work in solid modernity and work in the Social and Solidarity Economy is the existence of emancipated work. Emancipated work is a work of unique characteristics, it is not exploited work, since the ownership of the means of production of the cooperative is collective, it is not subordinated either because decisions are taken horizontally and mainly by consensus; it is not sanctioned, its fulfillment is given practically by the feeling of community of the cooperative; it is a work that allows creativity and human development.

The literature supports the evidence that stability generates predictability and long-term planning due to the commitment of the members; this condition is present in cooperative management thanks to the existence of emancipated labor. In the long term, the space-time relationship of half of the cooperatives that operate with generational change in a family manner stands out. Future planning has been translated into concrete strategies for market growth, improvement of infrastructure, equipment, and use of the principle of open membership, by recovering the creativity of the members in the General Assembly.

The research distinguishes two types of members, the leaders who act to guarantee collective stability through their shared commitment, direction, empathy, and recognition of the work done, which legitimizes them, and the followers who support the leaders' efforts to maintain labor stability; both under a social relationship that is not based on surplus value. It is argued that the cooperatives have the capacity to make decisions shared because the consequences derive from the work of both. In the analyzed cooperatives there are no restrictions to the deployment of leadership, the results show a better positioning of the cooperatives that have more leaders because having more members involved in management enhances democratic participation and collectively acquired knowledge. This was exemplified by the activities of the management positions of the Board of Directors and Supervisory Board, which, following the law and commitment to the organization, contribute strategically to production, commercialization, and sound accounting, activities on which the conditions of stability depend (although there are also leading members without management positions).

The limitation of the research has to do with the number of cooperatives interviewed and the characteristics of qualitative research, which prevents the results from being generalized to other cooperatives in Mexico City, other states, or the country. However, the results are theoretically framed in the structural tendencies experienced by the subjects of liquid modernity in neoliberalism, so they can be a reference. The originality and implications of the work lie in recognizing the ambivalence in the rationality of the subjects, when identifying the coexisting modernities to know what makes the stability of cooperatives possible in the urban environment, even when apparently only individualism and competition could prevail. On the other hand, emancipated work is a category little explored in the Social and Solidarity Economy, it emerged from both theoretical and applied analysis and made it possible to examine par- 
ticularities that are deployed from the form of organization and management presented by cooperatives that adhere to a greater extent to the principles and cooperative organization. Emancipated work requires the collective control of the means of production typical of the Social and Solidarity Economy to advance towards an alternative economy and contributes to creative and democratic work that improves the living conditions of the partners and consequently their own life, and even those of the following generations for the creation of loyalty, feelings of community, identity, and enjoyment of the fruits of work.

Keywords: Liquid modernity, solid modernity, cooperativism, Social and Solidarity Economy, labor uncertainty, labor stability, work. 


\section{Introducción}

El Estado de Bienestar surgió en los países socialdemócratas de Europa al final de la Segunda Guerra Mundial y se mantuvo como un mecanismo de contención al socialismo. En América Latina disminuyó los riesgos económicos individuales y colectivos que impone el libre mercado y asumió la responsabilidad del bienestar de los ciudadanos (Vázquez, 2005). La modernidad sólida es un concepto teorizado por Bauman (2003) para realizar una analogía con este período, en la física los sólidos se caracterizan por su estabilidad y rigidez, al igual que el proceso liderado por el Estado, el cual resultó en un proyecto de sociedad definido por objetivos que proporcionaron seguridad. En las relaciones sociales y el ámbito laboral esto contribuyó a generar solidaridad, confianza y amistad entre los trabajadores (Salazar, 2007) lo que aportó a configurar una identidad y comunidad urbana.

La política social de la modernidad sólida se basó en los principios de universalidad y de redistribución del ingreso, procuró el derecho al empleo y generó oportunidades para incluir a los marginados y excluidos de la competencia capitalista. El Estado brindó prestaciones sociales, educación, salud, vivienda y servicios públicos para mejorar las condiciones de vida de la población (Portilla, 2005; Duménil \& Lévy, 2011). El Estado del Bienestar fue una respuesta al capitalismo salvaje que reconocía las consecuencias del laissez faire en la vida de los ciudadanos (Ordóñez, 2012). El Estado se enfrentó a tensiones con los grupos empresariales por su injerencia en la regulación de los mercados y el respaldo legal a sindicatos que negociaban mejoras laborales para los trabajadores (Martínez, 2006). En México la modernidad sólida comprende el período de 1940 a 1982 y se constituyó bajo el modelo económico de Industrialización por Sustitución de Importaciones. Este modelo se distinguió por la preocupación estatal de la inserción de la población al mercado de trabajo, el incremento al salario real y las prestaciones laborales tales como vivienda y pensiones financiadas de manera tripartita (Ibarra, 2012).

El modelo que sustituyó al Estado del Bienestar fue el liberalismo remasterizado que dominó antes de la Primera Guerra Mundial, conocido como neoliberalismo. Para Bauman (2003) la reestructuración de la economía inició un proceso de licuefacción de los sólidos (estables) para dar lugar a los líquidos, estos en la física se caracterizan por un continuo cambio de forma (fluidez) por lo que Bauman llama al neoliberalismo modernidad líquida. Su analogía comienza con el desmantelamiento de las condiciones de estabilidad provistas durante la modernidad sólida, la disolución de la pertenencia social y seguridad laboral para pasar a un exacerbado individualismo (Hernández, 2016). En este período la libre competencia genera la quiebra de muchas micro y pequeñas empresas que son sometidas a la competencia internacional. El neoliberalismo concibe al Estado como un ente al servicio del mercado y el capital; en México este modelo económico inició en 1983 y terminó en 2018, se caracterizó por trasladar al mercado la responsabilidad del bienestar de la población, entre sus resultados están el incremento del sector informal, condiciones de precariedad laboral, migración y pobreza (Ibarra, 2012; Lee, 2014; Balcázar, 2019). En la legislación laboral mexicana se institucionalizaron las condiciones de incertidumbre laboral mediante las reformas a la Ley Federal del Trabajo de 2012, 
ya que se legalizaron los contratos temporales y el outsourcing, lo que disminuyó la capacidad de negociación colectiva, generó inestabilidad, falta de seguridad y certeza laboral (Cárdenas, 2015). Además, el sistema de pensiones en México como en muchos países latinoamericanos pasó a ser de capitalización individual y gestión privada, este sistema de pensiones tiene serias consecuencias para la clase trabajadora porque "no aumenta la cobertura, no garantiza pensiones dignas, no reduce los costos fiscales de los sistemas, no garantiza condiciones de autofinanciamiento ni el saneamiento del sistema a largo plazo" (Ulloa, 2017:9).

Entre las consecuencias de la modernidad líquida tenemos a finales de los años ochenta del siglo pasado una crisis de desempleo generalizada en América Latina, que da lugar, a una expansión sin precedentes del sector informal y al surgimiento de la Economía de Solidaridad (Razeto, 1993) que posteriormente algunos autores llamarán Economía Social y Solidaria. Esta se integra de formas de organización y producción alternativas en las que los trabajadores son dueños de los medios de producción, incluye al cooperativismo que surgió al inicio del capitalismo y perduró hacia la modernidad sólida y líquida. El contexto neoliberal está marcado por la falta de gasto público y prestaciones laborales (Musacchio, 2020) pero las cooperativas de producción resaltan como una vía para conseguir colectivamente condiciones de seguridad laboral semejantes a las que brindaba la modernidad sólida. En los trabajos iniciales en este campo, Razeto (1993) presenta evidencia de que en la Economía Solidaria existía mayor estabilidad en el trabajo.

Lee (2011) menciona que frente al desmantelamiento del Estado del Bienestar también se pueden generar condiciones de seguridad laboral y emocional desde las comunidades ( 0 cooperativas). Errasti, Bretos \& Nunez (2017) sostienen que las cooperativas son viables y tienen una ventaja cuando materializan la estabilidad laboral, la democracia y la solidaridad como parte básica de su funcionamiento. Sin embargo, estos mismos autores aluden a la tesis de la degeneración del cooperativismo que plantea que las cooperativas en ocasiones abandonan las formas democráticas para volverse empresas capitalistas convencionales debido a las presiones del mercado neoliberal, al desarrollar una gestión que no prioriza los valores y principios del cooperativismo. Por lo que el objetivo del artículo es analizar la gestión y condiciones laborales de los socios de pequeñas cooperativas familiares de la Ciudad de México a partir de su cercanía o alejamiento a las características del trabajo en la modernidad líquida, sólida y la Economía Social y Solidaria, esto con el fin de conocer las características del trabajo que se presenta en las cooperativas. Las preguntas que se contestan en este artículo son: ¿Las condiciones laborales que se presentan en el Estado del Bienestar son iguales a las que se propone alcanzar la Economía Social y Solidaria? y siendo dos marcos teóricos distintos ¿Cuáles entonces son las particularidades del trabajo en la Economía Social y Solidaria?

La estructura del artículo es la siguiente: en el primer apartado se analiza el surgimiento de la Economía Social y Solidaria como alternativa al capitalismo y sus diferencias en el ámbito laboral con la modernidad sólida y líquida. En el segundo apartado se explica la metodología de la investigación, la selección de las cooperativas se realizó mediante la técnica estadística del análisis discriminante; se aplicaron entrevistas semiestructuradas al presidente o encargado del Consejo de Administración para conocer la subjetividad de los sujetos sobre la gestión y las 
acciones en torno a los elementos identificados de estabilidad laboral; las respuestas se analizaron con el método de categorización y el software Atlas.ti.8. En el último apartado se analizan las respuestas usando las categorías identificadas: relación capital-trabajo, espacio-tiempo y comunidad-individuo; para analizar: las características de la estabilidad económica en las cooperativas, su capacidad de visualizarse a largo plazo, el organigrama cooperativista (los socios líderes y seguidores), la toma democrática de decisiones mediante la Asamblea General entre los socios líderes y seguidores y la responsabilidad en las cooperativas urbanas analizadas. Se concluye que efectivamente las cooperativas tienen similitudes con la modernidad sólida en términos de estabilidad; sin embargo, se alcanza un nivel de independencia del trabajo que no existe en la modernidad sólida, al presentar características del trabajo emancipado (Arruda, 2010) que procura la Economía Social y Solidaria.

\section{Economía Social y Solidaria: rechazo a la incertidumbre laboral de la modernidad líquida y cercanía a la seguridad laboral de la sólida}

La Economía Social y Solidaria (en adelante ESS) surgió en los años ochenta en América Latina como una respuesta al desempleo y quiebra de pequeñas empresas que asoló la región (Razeto, 1993) a partir de la implementación de la modernidad líquida. De acuerdo con Utting, Van Dijk \& Matheï (2014) la ESS está integrada por organizaciones que en un sistema producen, comercializan, intercambian y distribuyen bienes y servicios. Las organizaciones se guían por valores que tienen como eje rector la solidaridad; pero también la socialización de los excedentes, autogestión, reciprocidad y acciones en pro de la sustentabilidad ambiental. Los principios se basan en la autonomía, gestión y propiedad colectiva de los medios de producción (Arruda, 2010). Los objetivos de la ESS están asociados con la satisfacción de las necesidades sociales locales, la búsqueda de la seguridad de los medios de vida, equidad, protección social y la generación de una menor huella ecológica (Utting, Van Dijk \& Matheï, 2014:14). La ESS aporta alternativas a los problemas generados por el capitalismo tales como la pobreza, la injusticia y la destrucción de la naturaleza, mediante iniciativas que tienen excedentes; pero que deben ser reinvertidos con fines sociales mediante la lógica de la solidaridad que subordina a la del mercado (Marques, 2014).

De acuerdo con Marques (2014) actualmente se conciben tres perspectivas de la ESS: 1) una iniciativa orientada al mercado que resuelve algunos de sus fallos y genera cierta cohesión social; 2) una vía de desarrollo local impulsada por políticas públicas; y 3) un modelo económico alterno de transformación social que crea relaciones de producción no capitalistas para reorganizar la propiedad, el trabajo y la gestión mediante lo colectivo al satisfacer las necesidades 
de la sociedad. Aquí se retoma esta última perspectiva y se entiende a la ESS como un sistema económico alternativo al capitalismo que contribuye a crear una sociedad más igualitaria. La ESS tiene como precedente originario a las cooperativas provenientes del pensamiento de los socialistas utópicos, las cuales datan del inicio del capitalismo conocido como capitalismo salvaje a inicios de la revolución industrial (1844) su objetivo "era oponerse a la miseria provocada por los bajos salarios y las condiciones inhumanas de trabajo" (Núñez, 2017: 42).

El cooperativismo es una de las formas de organización productiva con mayor historia en la ESS, posee una administración, gestión, planeación y deliberación democrática; que al realizarse empodera a los socios, genera un sentido de comunidad, identidad y pertenencia (Verschuur, 2018). De acuerdo con Utting, Van Dijk \& Matheï (2014) la democracia también permite a los socios tomar decisiones difíciles legítimamente al proteger su fuente de trabajo y construir fondos sociales. La deliberación horizontal mediante la participación y discusión de los socios por vías formales e informales antepone la preferencia colectiva a la elección individual. Todas estas características se contraponen a las que predominan en el capitalismo, especialmente en la modernidad líquida donde la competencia y el interés individual están al servicio de la acumulación de capital (Marques, 2014; Nunez, 2017). Por lo que al ir a contracorriente de la lógica capitalista muchas veces su gestión no llega a presentar el nivel de desarrollo y objetivos que plantea la ESS. Para realizar el análisis de las causas, alcances y cercanía de las cooperativas a la estabilidad (modernidad sólida y ESS) o incertidumbre y falta de democracia (modernidad líquida) se toman como referentes las transformaciones y relaciones entre: capital-trabajo, espacio-tiempo y comunidad e individuo.

\section{La relación capital-trabajo}

La relación capital-trabajo en el capitalismo se caracteriza porque el trabajo está supeditado al incremento del capital. El productor requiere, por un lado, generar valores de uso que tengan valor de cambio en el mercado y, por otro, producir una mercancía cuyo valor sea mayor a las mercancías adquiridas para producirla, es decir, requiere generar plusvalor, así "el proceso de trabajo se transforma en un instrumento del proceso de creación de plusvalía y se diferencia del proceso de trabajo -como condición de vida del hombre- del proceso de valorización -como condición de acumulación del capital" (Odriozola \& Colina, 2015:9).

Los diferentes medios para incrementar la plusvalía determinaron la forma que la relación capital-trabajo poseyó en cada una de las modernidades, en la líquida provoca la incertidumbre e inseguridad. Al ser eliminado el compromiso legal entre empleadores y empleados (Bauman, 2017) predominan los contratos temporales, salarios reales bajos (o variables), movilidad del lugar de trabajo, horarios flexibles y falta de prestaciones sociales (Pérez, 2019). Sennett (2010) identifica en este período una administración no jerárquica, supervisión remota de los trabajadores por medio de la tecnología, relaciones virtuales e inmediatez que impide planificar la vida. Por el contrario, en la modernidad sólida la relación capital-trabajo fue definida por la estabilidad laboral lograda con la mediación estatal entre trabajadores y capitalistas, en el trabajo se procuraba la disciplina, jerarquía y autoridad. Las condiciones de 
seguridad y estabilidad laboral de acuerdo con Bauman (2003) provenían de: salarios fijos, lugar de trabajo inmóvil, jornada de trabajo definida y prestaciones sociales, las cuales permitieron generar en los sujetos confianza, reconocimiento, vocación y orgullo, el "trabajo era el pilar sobre el que se construían y giraban las demás dimensiones de la vida” (Pérez, 2019: 94). Para Sennett (2010) el trabajo estable configuró el carácter, el cual es una expresión emocional de largo plazo asociada al compromiso y ética, importante para entablar relaciones humanas de persona a persona y con una comunidad. No obstante, el trabajo asalariado con o sin estabilidad laboral, tanto en la modernidad sólida como en la líquida, implica que los trabajadores continúen siendo despojados del producto de su trabajo, el sentido de su vida, pericia y conocimiento; para ser propiedad de los capitalistas mediante trabajo sedentario, repetitivo y alienante (Pérez, 2019).

Por otro lado, la meta laboral de la ESS es superar cualquier forma del trabajo asalariado para transitar hacia el trabajo emancipado, el cual requiere "la democratización del derecho a la propiedad individual y social de los medios de producción" (Arruda, 2010: 265). La propiedad social determina la autogestión de los trabajadores como productores y gestores protagonistas de su propio desarrollo como seres humanos. El trabajo emancipado constituye el fin último de la ESS, éste aporta a la construcción de una sociedad que conquista la creatividad, el poder y el saber para dedicarlo al desarrollo del ser humano (objetivo y subjetivo). Además, recupera la expresión espiritual y material de la vida, así como la satisfacción de las necesidades sociales. Colectivamente se hace efectiva la satisfacción y el gozo del excedente que requiere una menor cantidad de tiempo de trabajo socialmente para producirlo, con la ayuda de medios tecnológicos para disminuir los costes humanos y ambientales, redefiniendo así la eficacia. A diferencia del capitalismo que realiza una apropiación privada del trabajo para la acumulación, lo que lo vuelve deshumanizante, obligatorio y alienante. El trabajo emancipado requiere también de un proceso educativo y cultural de socialización del poder y la riqueza basado en los principios y valores de la cooperación, solidaridad, democracia y justicia; proceso que puede darse a través de una autoeducación y autoconstrucción del ser humano.

\section{La relación espacio-tiempo}

El capital no requiere personas, porque contrata tiempo de trabajo de la mercancía fuerza de trabajo y el espacio laboral para transformarlo a partir de las necesidades de la valorización del capital y del desarrollo de las fuerzas productivas. La relación espacio-tiempo en la modernidad líquida está determinada por la inestabilidad de la jornada laboral e incertidumbre que genera precariedad en el empleo e incapacidad de prever a mediano y largo plazo lo personal y colectivo (Núñez, 2017). La dinámica laboral cambiante del capitalismo flexible está determinada también por la rapidez e inmediatez de los avances tecnológicos que facilitan la precariedad de los vínculos humanos (Bialakowsky \& Hermo, 2014). En la actualidad incluso se considera la fluidez, el desapego, la agilidad y la competencia como cualidades superiores, hay una valoración positiva del riesgo y la incertidumbre que permiten la falta de compromisos (Béjar, 2000). Por el contrario, en la modernidad sólida la relación "tiempo/espacio significaba 
horario, lugar de trabajo, y salario" (Salazar, 2007: 8), además de prestaciones sociales que definían condiciones de seguridad, las cuales permitían visualizarse y mantener una previsibilidad a largo plazo. Sennett (2010) concuerda en que el trabajo en el Estado del Bienestar se caracterizó por contratos (reglas fijas), empleos lineales, la rutina, lo duradero, protección sindical y logros acumulativos que permitieron la comunidad de trabajo. En la ESS de acuerdo con Arruda $(2005 ; 2010)$ la noción espacio-tiempo enfatiza la continuidad entre pasado, presente y futuro, es decir, la sociedad mediante el trabajo pasado (tiempo vivido) determina el entorno colectivo-comunitario presente y, a su vez el trabajo presente influye en la vida de las futuras generaciones. Por eso, el esfuerzo de la sociedad requiere la búsqueda del trabajo emancipado para determinar un momento histórico que humanice al ser.

\section{La relación comunidad e individuo}

Desde la perspectiva de Marx los trabajadores "son individuos que entran en relaciones con el mismo capital, pero no entre sí. Su cooperación comienza en el proceso de trabajo, es decir, cuando ya han dejado de pertenecerse a sí mismos. Al entrar en el proceso de trabajo son absorbidos por el capital" (Odriozola \& Colina, 2015:10). En la modernidad líquida la relación comunidad e individuo se enfoca en el individuo, esto es, porque la incertidumbre estructural y la competencia frenan los valores de cooperación y solidaridad al ver a los demás como una amenaza en el mercado laboral (Leira, 2017). El individualismo es un estado de irresponsabilidad derivado de no querer asumir compromisos (Bauman, 2003) porque el sujeto fue convencido de que "cada individuo humano [debe] buscar y encontrar (o interpretar) soluciones individuales a problemas producidos socialmente" (Bauman, 2017: 16). Predomina la búsqueda subjetiva de la sensación de libertad, como una condición para alcanzar un futuro mejor, visión respaldada en la existencia de estímulos para la satisfacción personal (Lee, 2011). El individuo neoliberal se caracteriza porque la independencia y autosuficiencia generan una crisis de identidad permanente en un contexto de mínimas obligaciones; es esencialmente antisocial considera que son las cosas las que lo acercan o alejan del placer y de la felicidad, es calculador y ambicioso (Valverde, 2014).

La seguridad en la modernidad líquida se obtiene al seguir las normatividades, debido a que se delegan las responsabilidades que no implican una guía de acción para evitar la fatiga de ser responsables individualmente (Bauman, 2017). Para Sennett (2010) el individualismo corroe el carácter, es decir, la ética de los sujetos, al no permitir una narración colectiva, ni generar lealtad, compromiso y vínculos, traducido socialmente en la desintegración de la comunidad.

La relación entre comunidad e individuo en la modernidad sólida, por otro lado, aportaba a la existencia de una comunidad que funcionaba como medio de estabilidad a largo plazo, proveía de seguridad emocional y material, además de excluir a otras comunidades (González, 2007). La modernidad sólida permitió establecer una comunidad en el entorno urbano al generar espacios de estabilidad, arraigo, vínculos afectivos, identidad y progreso colectivo; "la clase trabajadora entendía que actuando colectivamente podía mejorar sus condiciones" (Leira, 2017: 112). La confianza existía en términos formales mediante contratos, pero siempre 
con un respaldo informal proveniente de la ética, lealtad, disciplina, compromiso y servicio (Sennett, 2010); valores actualmente percibidos como anacrónicos y de estancamiento personal.

En el caso de la ESS la comunidad es la base del nuevo proyecto económico y las relaciones sociales, las organizaciones surgen para atender las necesidades de la comunidad y buscan el control y la gestión racional de las condiciones básicas de la vida (Coraggio, 2009). Los principios de la ESS propician y fortalecen a la persona como un fin en sí mismo, el trabajo en movimiento da sentido a la vida individual como vida creativa que la hace un acto propio y no un acto para otro (Valverde, 2014:33) a partir de la cohesión social y solidaridad en comunidad (Fonteneau, et al., 2010).

Las tres relaciones en la modernidad sólida como en la líquida presentan a "los seres humanos como hacedores de la historia bajo condiciones que no han podido elegir" (Bauman, 2017:22). En ese sentido autores como González (2007) y Salazar (2007) han reconocido que existe una ambivalencia en la identidad de algunos sujetos durante la modernidad líquida por los imaginarios provenientes de la modernidad sólida; debido a la presencia de comportamientos y conductas que generan el anhelo de seguridades pérdidas, certeza y experiencias comunitarias ante la incertidumbre. Para Salazar (2007) la creación de condiciones de seguridad en la modernidad líquida posibilita el escape al destino del hombre moderno. En la ciudad, la comunidad aún puede materializarse a través de "la familia, en tanto reducto último de entendimiento común" (González, 2007:19). Sin embargo, Sennett (2010) reconoce la complejidad de intentar transmitir los valores de lealtad y compromiso cuando no se practican en la vida cotidiana. Lee (2011) también ha argumentado que las relaciones sociales líquidas pueden resolidificarse en comunidades mediante la capacidad de agencia (motivaciones personales) cuando el individualismo genera estragos sociales. Sin embargo, la búsqueda únicamente de la modernidad sólida en la modernidad líquida presenta un objetivo menor al de la ESS, el cual consiste en conformar un sistema económico alternativo al capitalismo (Marques, 2014) en la búsqueda del trabajo emancipado.

\section{Metodología}

La metodología fue mixta, para el análisis cualitativo se utilizó la entrevista semiestructurada (Geilfus, 2002) en la que a partir de la aproximación teórica se indagó en las siguientes relaciones y categorías de análisis identificadas: capital-trabajo, espacio-tiempo y comunidad e individuo. Del cooperativismo se retomó para la construcción de la entrevista, los principios para la gestión interna: control democrático, participación democrática y autonomía e independencia; con énfasis en la democracia mediante el organigrama (Asamblea General, Consejo de Administración y Consejo de Vigilancia). Las entrevistas fueron aplicadas a los representantes legales de las cooperativas seleccionadas, es decir, al presidente o en su defecto al encargado del Consejo de Administración por el mayor conocimiento que tienen de la organización; en el caso del presidente por la representación legal que ejerce (LGSC, 1994). Las entrevistas 
semiestructuradas evitan predisponer las respuestas y se caracterizan por ser flexibles a pesar de basarse en preguntas acotadas, motivan al entrevistado a realizar aclaraciones.

El análisis de las entrevistas se realizó con el método de categorización sugerido en la literatura para el análisis de texto (Fernández, 2006; Muñoz \& Sahagún, 2017). El método sirve para transcribir y sintetizar mediante palabras o frases las respuestas extensas y similares de los entrevistados. Las categorías se identificaron usando la codificación abierta y teórica de los temas, también se analizaron las subcategorías de los elementos de cada tema (Casado, 2018; González, Mortigo \& Berdugo, 2014). Las categorizaciones se presentan a través de redes elaboradas en el programa Atlas.ti.8, enlazadas por líneas punteadas rojas entre las categorías y subcategorías, y por líneas negras entre subcategorías, el enlace se apoya de etiquetas de relación. Las redes se sustentan en el método de coocurrencias que utiliza las frecuencias identificadas por el software entre las densidades de las subcategorías con base en las relaciones propuestas por los investigadores (Varguillas, 2006; Muñoz \& Sahagún, 2017). Se presenta el enraizamiento y densidad de las categorizaciones, el enraizamiento es el número ubicado al lado de la letra E que muestra las citas que respaldan la categoría propuesta; abajo del enraizamiento está la densidad marcada con una $\mathrm{D}$, esta muestra las veces que se relaciona una categoría semánticamente con otras (Martínez, 2001). Las categorizaciones analizadas en el texto se distinguirán cuando estén escritas en letras cursivas y entrecomilladas.

La selección de las cooperativas a estudiar se realizó a través de la técnica multivariada del análisis discriminante para variables dependientes categóricas y cuantitativas independientes a fin de clasificar a las cooperativas exitosas y no exitosas (Madrid \& Cerón, 2012). La metodología fue presentada ampliamente en Luvián, Rosas \& Ramírez (2019). La base de datos utilizada para realizar las discriminaciones fue la del "Diagnóstico económico sobre cooperativismo del Distrito Federal" de 2015, con 192 cooperativas representativas al 90\% de confianza de 1,589. Las variables categóricas dependientes fueron las cooperativas exitosas y cooperativas no exitosas, las independientes fueron: apropiada gestión cooperativa y viabilidad económica. Sirvieron para realizar dos análisis discriminantes con una clasificación de grupos a priori verificada estadísticamente en el programa STATA 13.0.

El análisis discriminante para la apropiada gestión cooperativa consideró de la base de datos las siguientes variables independientes con sus respectivas cuantitativas: poseer un organigrama cooperativista (Camilletti, et al., 2005), la toma democrática de decisiones (Ramírez, coord. 2013), gestión democrática en las actividades de Asamblea General (LGSC, Art.36, 1994) y operación basada en principios cooperativistas (Errasti, Bretos \& Nunez, 2017). El análisis discriminante para la viabilidad económica consideró de la base de datos las siguientes variables independientes cuantitativas: cumplir cinco años de operación ininterrumpida (González \& San Bartolomé, 2009), recibir el pago económico a tiempo (Meitta, Cavina \& Franco, 1996), desarrollo de las ventas (Sánchez, 2001) y autoclasificación del ciclo de vida. El cruce de 22 cooperativas con viabilidad económica y 130 con apropiada gestión cooperativa determinó a 12 cooperativas exitosas con cinco años de operación, las cooperativas no exitosas fueron las que no cumplieron ambas categorías. Tres no pudieron ser contactadas por inexistencia, indisposición o desaparición, adicionalmente una cooperativa fue descartada, tras entrevistarla 
y descubrir que no funcionaba como una organización democrática, por lo que se estudiaron a ocho cooperativas de las cuales siete resultaron ser cooperativas familiares y una integrada sólo por amigos.

\section{Resultados: Análisis de las estrategias de gestión de las pequeñas cooperativas de la Ciudad de México}

Las ocho cooperativas que se analizan están ubicadas en cuatro de las dieciséis Alcaldías de la Ciudad de México, destaca la Alcaldía de Xochimilco porque ahí se ubican cuatro de las ocho con 21 socios (véase la tabla 1). Esta Alcaldía tiene un origen prehispánico y una extensión territorial de 12,517 ha, de las cuales el $80 \%$ es suelo de conservación, aunque también se contabilizan poblados rurales, de producción rural agroindustrial y principalmente recursos naturales forestales ${ }^{1}$. Solamente dos de las ocho cooperativas seleccionadas son agrícolas (CA1 y CA2), cuatro son de producción (CP1, CP2, CP3 y CP4) y dos de servicios (CS1 y CS2). En 2018 las cooperativas tenían cinco, siete, diez y once años de operación respectivamente (véase la tabla 1). Siete de las cooperativas aceptaron responder el anexo estadístico de la entrevista, a través del cual, se proporciona información de la edad de los socios, lo que arroja el hecho de que $56.76 \%$ (21 socios) habían nacido durante la modernidad líquida (1983-2020) correspondientes al rango de edad de 20 a 30 y 31 a 40 años. El 43.24\% (16 socios) nacieron durante la modernidad sólida (1950-1982) identificados en el rango de los 41 a 50 años hasta los 71 a 80 (véase la tabla 1 ).

Algunas de las características generales de las ocho cooperativas urbanas son que el 87.5\% han sido creadas con la participación de familiares y el $12.5 \%$ sólo con amigos (véase la tabla 1); de acuerdo con Salazar (2007) la familia es el medio donde aún puede materializarse la comunidad en el neoliberalismo. A pesar de que en las cooperativas hay más socios con una subjetividad moldeada por la modernidad líquida (véase la tabla 1), conforme a Lee (2011) indistintamente el trabajo colectivo ya sea familiar o con amigos en las cooperativas posibilita la solidificación de las relaciones sociales líquidas (individualistas); al buscar la mejora de la condición de vida a través de la cooperación, sin pensar como un obstáculo las obligaciones como en la modernidad líquida (Bauman, 2017). 


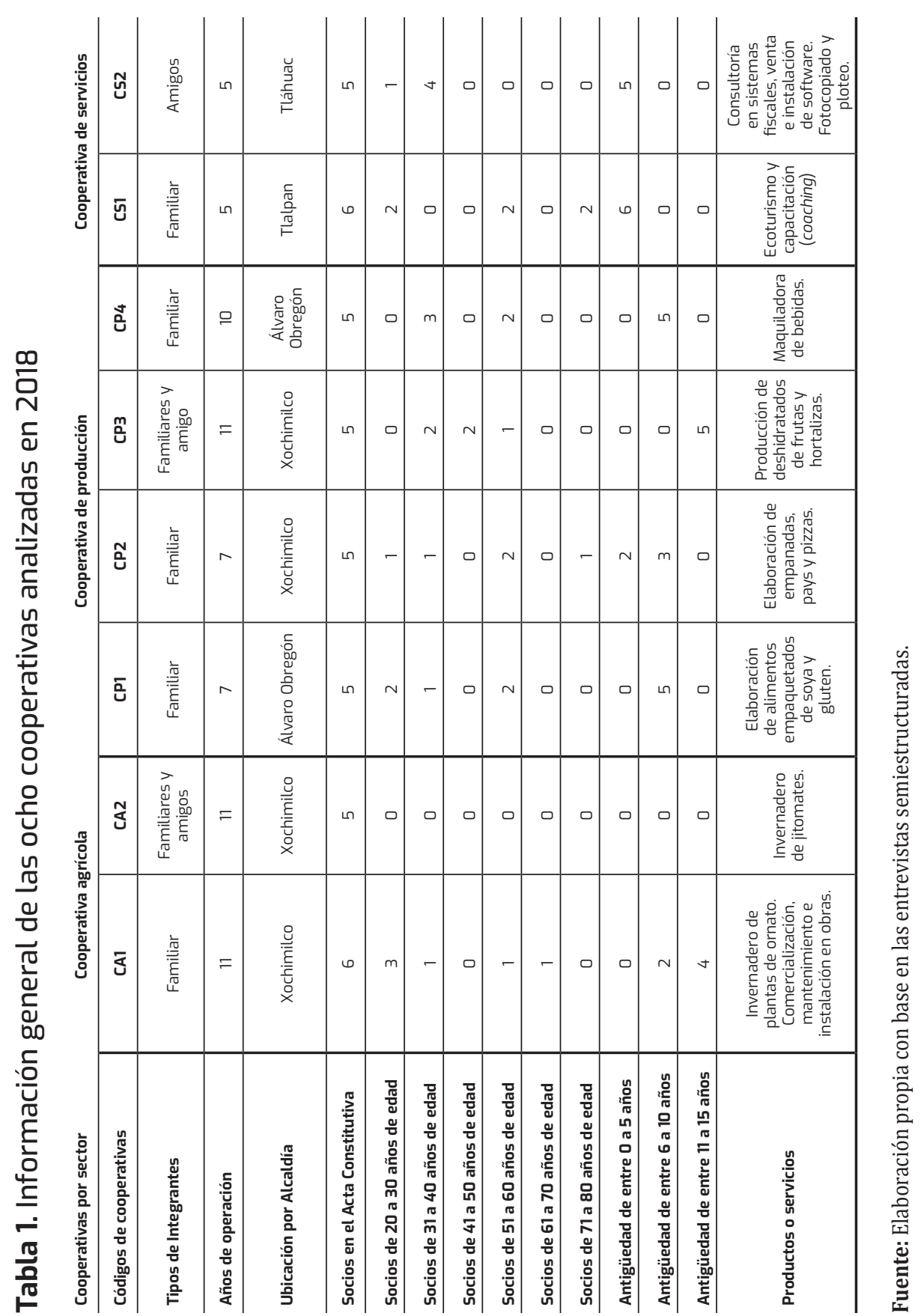




\subsection{Características de la estabilidad económica y la visualización del largo plazo}

Las ocho cooperativas tienen por lo menos cinco años de operación ininterrumpida (González \& San Bartolomé, 2009) (véase la tabla 1) y han creado colectivamente distintas condiciones de "estabilidad laboral", subcategoría relevante por su densidad (véase la red 1) y opuesta a la relación capital-trabajo imperante en la modernidad líquida caracterizada por la inestabilidad laboral (Bauman, 2017).

La relación capital-trabajo no se presenta desde una lógica de subordinación del trabajo al capital, sino con una "estabilidad laboral" propia de la ESS que tiene semejanzas con la modernidad sólida, pero en este caso la estabilidad deriva de la forma organizativa de las cooperativas. Siete cooperativas (excepto la CA2) han definido el equivalente a un "salario fijo" (véase la red 1) además, en las cooperativas hay reparto de rendimientos, el cual incluso puede aumentar al haber mayores excedentes socializados acorde a los valores de la ESS (Utting, Van Dijk \& Matheï, 2014). Siete tienen un "lugar de trabajo estable" que genera un arraigo e identidad, excepto la CP4 que renta una nave industrial para producir bebidas (véase la red 1). Cinco cooperativas tienen "horarios fijos de trabajo" (CA1, CP1, CP3, CP4 y CS2) no así la CP2 que extiende su jornada cuando satisface grandes pedidos y la CS1 que al ser turística su jornada depende de los visitantes (véase la red 1). Cuatro organizaciones (CP2, CP3, CS1 y CS2) han conformado el fondo de previsión social, enfocado a un "ahorro destinado a gastos médicos" (véase la red 1). Las subcategorías que conforman la "estabilidad laboral" están ligadas al principio de participación económica de los miembros; también a los objetivos de la ESS de protección social y seguridad de los medios de vida (Utting, Van Dijk \& Matheï, 2014).

La relación capital-trabajo en la modernidad sólida determinaba la relación espacio-tiempo al permitir planificar la vida y visualizarse a futuro (Salazar, 2007). En la modernidad líquida imperan las relaciones de corto plazo por la incertidumbre estructural. En cuatro cooperativas familiares (CA1, CP1, CP2 y CP4) la subcategoría "estabilidad laboral" ha resultado a largo plazo en "operar con cambio generacional", al planificar la vida laboral con los hijos de los socios que posteriormente se integraron (véase la red 1). En estas cuatro cooperativas familiares la relación espacio-tiempo se asemeja más a la de la ESS (Arruda, 2005;2010) donde el trabajo pasado, presente y futuro se ponen al servicio de la segunda generación, beneficiando a la primera con una continuidad para ambas a futuro. Otro resultado de la previsibilidad y estabilidad ha sido la "creación de jubilaciones" tema prioritario sólo atendido en la CS2, lo cual en parte se explica porque los socios son asesores en temas fiscales (véase la red 1) pero sorprende al estar compuesta por socios nacidos durante la modernidad líquida (véase la tabla 1).

En la entrevista se indagó al respecto de la "visualización a tres años" considerando que las cooperativas en 2018 tenían respectivamente: cinco, siete, diez y once años de operación (véase la tabla 1). La planeación a futuro es producto de la relación espacio-tiempo por la "estabilidad laboral", en tres cooperativas (CA2, CP3 y CS1) implica un "cambio generacional a futuro" (véase la red 1). En sentido opuesto, dos cooperativas (CS1 y CA2) planean el "retiro de miembros de mayor edad" (véase la red 1). Respecto a cuestiones productivas: en cuatro 


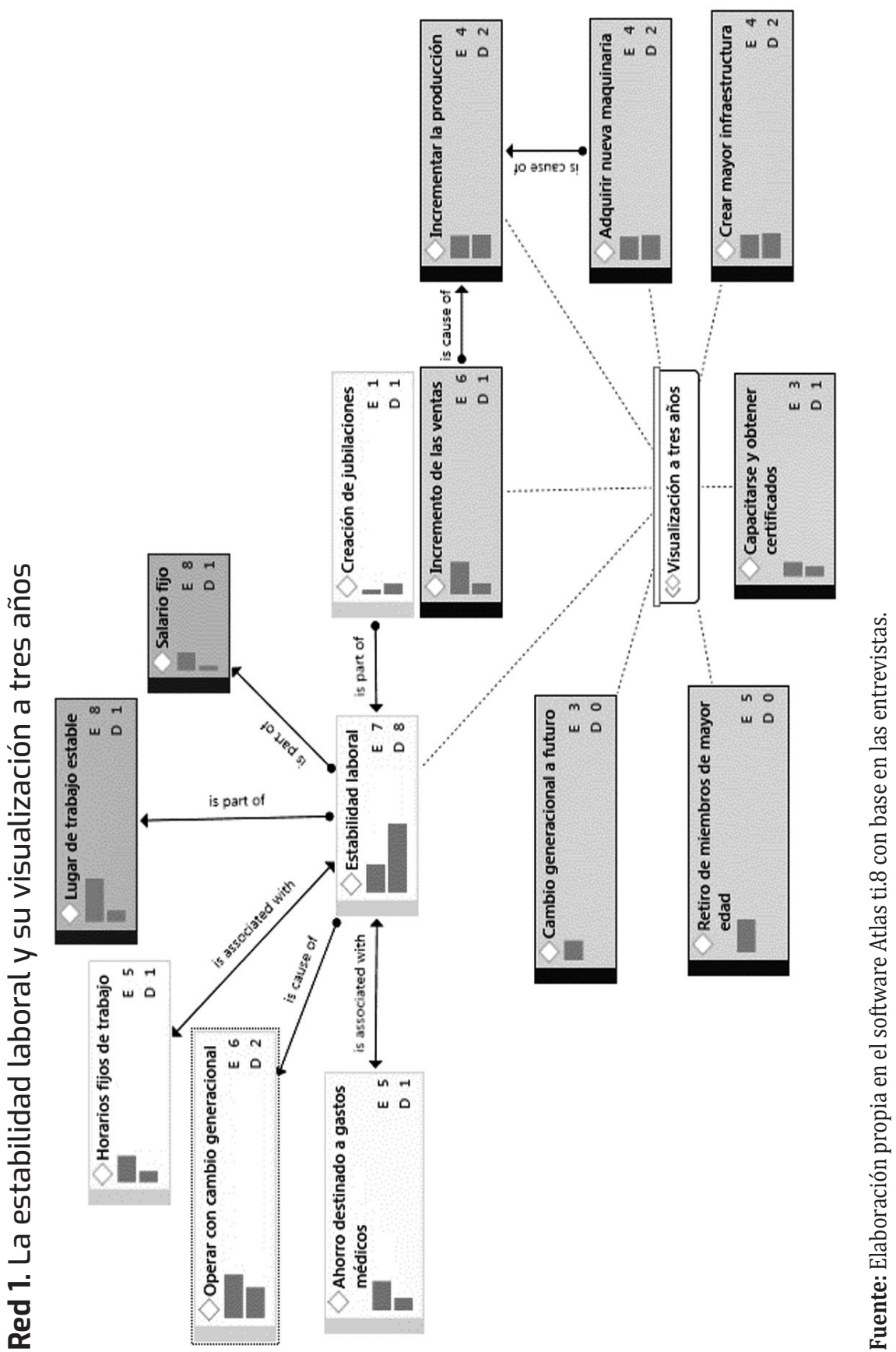


cooperativas (CP2, CP3, CA2 y CP4) van a "adquirir nueva maquinaria" para evitar ciertas limitaciones productivas, en tres (CP3, CA1 y CA2) para "incrementar la producción" y en cinco de ellas (CS1, CP1, CP2, CP3 y CA1) ante el "incremento de las ventas" (véase la red 1). En tres cooperativas (CP2, CP3 y CP4) la visión a futuro también implica "crear mayor infraestructu$r a "$; lo que en la modernidad sólida externaba un arraigo al lugar de trabajo. Dos casos (CA2 y CS2) mencionaron la necesidad de "capacitarse y obtener certificados" (véase la red 1). Las subcategorías del espacio-tiempo a futuro presentan características del trabajo emancipado al volver a los socios protagonistas de su desarrollo como dueños de los medios de producción (Arruda, 2010).

\subsection{Los tipos de socios en las cooperativas}

La democracia interna en las organizaciones de la ESS es atribuida inherentemente a sus integrantes (Verschuur, coord., 2018) de acuerdo con las teorías sobre el liderazgo se identifican dos tipos de socios cooperativistas: líderes y seguidores (véase la tabla 2). En las cooperativas lo ideal es que se presente un liderazgo compartido (Romero, 2018) el cual debe descentralizarse para ser distribuido y garantizar la participación democrática y activa de los socios en la gestión, dirección y toma de decisiones; para que las responsabilidades sean equitativas y colectivas. Los líderes se caracterizan por su compromiso con la organización, confianza, conocimiento, capacidad de análisis, de inspirar, dirigir, transmitir, ser empáticos y alcanzar objetivos (Sánchez, et al., 2014; Romero, 2018).

\section{Tabla 2. Tipos de socios en las cooperativas analizadas}

\begin{tabular}{l|c|c|c} 
Cooperativa & Socios líderes & Socios seguidores & $\begin{array}{c}\text { Total de socios en el } \\
\text { Acta Constitutiva }\end{array}$ \\
\hline CA1 & 4 & 2 & 6 \\
\hline CA2 & 2 & 3 & 5 \\
\hline CP1 & 4 & 1 & 5 \\
\hline CP2 & 4 & 1 & 5 \\
\hline CP3 & 3 & 2 & 5 \\
\hline CP4 & 2 & 3 & 5 \\
\hline CS1 & 2 & 4 & 6 \\
\hline CS2 & 3 & 2 & 5 \\
\hline
\end{tabular}

Fuente: Elaboración propia con la información de las entrevistas.

De acuerdo con las entrevistas y la definición anterior, los socios líderes en el origen de las ocho cooperativas contribuyeron a la constitución legal, por tener un mayor conocimiento previo y experiencia en la actividad productiva; aportaron propuestas para superar el autoempleo 
informal y cuestionaron el individualismo al brindar soluciones a problemas asumiendo responsabilidades (Bauman, 2017). Estos socios en las cooperativas ya constituidas se convirtieron en presidentes o encargados del Consejo de Administración, asumieron un liderazgo con legitimidad (aunque posteriormente surgieron líderes sin cargos). Los seguidores se clasifican así por sus dificultades para externar sus opiniones en Asamblea, sobredimensionar al líder (Romero, 2018) y adherirse principalmente a sus propuestas para mantener las condiciones de seguridad (Bauman, 2017). Por eso resalta cada una de las cinco cooperativas (CA1, CP1, CP2, CP3 y CS2) con más de 60\% de socios líderes que son las más democráticas; en oposición a las tres cooperativas (CA2, CP4 y CS1) con menos de $40 \%$ de socios líderes que son las menos democráticas (véase la tabla 2).

El comportamiento de los socios va más allá de lo que explican Salazar (2007) y Lee (2011) sobre la existencia de una ambivalencia entre los imaginarios de los sujetos provenientes de la modernidad sólida y líquida que deriva en el anhelo de seguridad. Tanto los socios líderes como los seguidores presentan características de trabajadores emancipados (Arruda, 2010), puesto que participan con su trabajo en una producción de bienes cuyo proceso de valorización no se sustenta en la plusvalía.

\subsection{El organigrama cooperativista y los socios}

Respecto al uso del organigrama para el cumplimiento de los valores de transparencia y honestidad, además de los principios de control democrático del cooperativismo y de gestión colectiva de la ESS (Verschuur, coord., 2018) los socios de las ocho cooperativas participan mayormente de manera "mensual" o "cada que es necesario" en "la Asamblea General" para el "análisis de nuevos proyectos", subcategoría con alto enraizamiento y densidad (véase la red 2).

El actuar de los socios de manera similar a las teorías está comprometido con la organización (Romero, 2018) y el progreso colectivo (Leira, 2017). Algunos socios líderes con cargos de dirección en seis cooperativas (CA1, CA2, CP1, CP3, CP4 y CS1) realizan "actividades del Consejo de Administración" al ser "responsables de la producción", siete de ellos (incluyendo la CP2) también se encargan de la "creación de redes de comercialización" (véase la red 2). La densidad de la subcategoría muestra que los líderes con cargo en siete cooperativas (excepto la CP4) también están atentos a "mantener una sana contabilidad" interna (véase la red 2). En cuanto a las "actividades del Consejo de Vigilancia" éste es el Consejo menos utilizado en sus atribuciones legales al "supervisar la producción" (CP2 y CP4) y "supervisar las cuentas de banco" (CA1, CA2 y CS2). Cuatro cooperativas (CP1, CP3, CS1 y CS2) delegan la vigilancia al "emplear un contador externo" (véase la red 2), tres no supervisan al Consejo de Administración por la confianza de ser familiares y trabajar con cambio generacional (excepto la CP1) y la CA2 por realizar la contabilidad internamente. Las entrevistas muestran que los socios seguidores son quienes se suman a los acuerdos (reglas) de la Asamblea General, al trabajar y desempeñar las ocupaciones asignadas (Bauman, 2017; Romero, 2018) comparten con los socios líderes la búsqueda de seguridad que la cooperativa provee para ambos. 


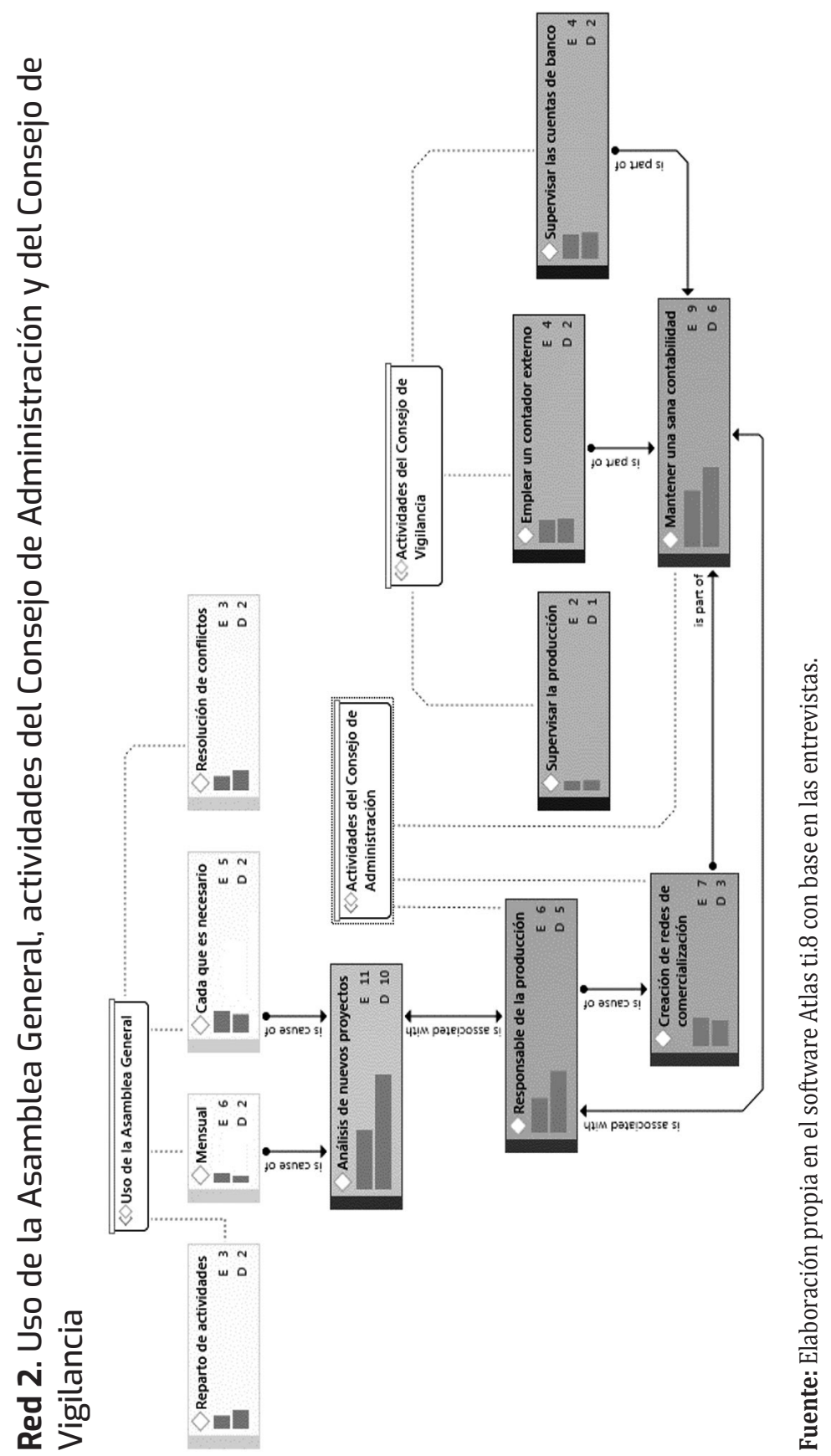


Cada una de las cinco cooperativas (CA1, CP1, CP2, CP3 y CS2) con más del 60\% de líderes (véase la tabla 2) tienen un favorable desenvolvimiento en el mercado ${ }^{2}$ debido a una mayor atención a los aspectos de la gestión y el trabajo porque la participación democrática crea comunidad (Verschuur, coord., 2018). Por ejemplo, en tres cooperativas familiares (CA1, CP1 y CP2) que "operan con cambio generacional" (véase la red 1) el liderazgo se intercambia con los hijos independientemente de si tienen cargos legales; llegan a tener un mayor peso en la CA1 y CP1 al haber concluido estudios universitarios relacionados a la actividad productiva. Se potencian mutuamente los conocimientos, la responsabilidad y el cálculo porque recae en más socios, a diferencia de las cooperativas con más socios seguidores. Incluso el trabajo en las cooperativas familiares fortalece la relación espacio-tiempo en los términos de la ESS, cuando la pasada generación beneficia a la presente y viceversa compartiendo un futuro (Arruda, 2010). La CP3 y CS2 son ejemplos de organizaciones con tres socios líderes cada una que, aunque exitosas podrían tener un mejor desempeño económico y promover el liderazgo compartido con los otros socios seguidores (véase la tabla 2).

En cada una de las tres cooperativas (CA2, CP4 y CS1) con menos de 40\% de socios líderes (véase la tabla 2) los aspectos trascendentales de la gestión se basan en las propuestas de los líderes, lo que las limita, por ejemplo: el éxito en el mercado de la CA2 se basa en la estrategia de comercialización con empresas transnacionales, el vínculo fue gestionado por la presidenta del Consejo de Administración; pero ningún otro socio ha buscado adherirse a redes solidarias, mejorar el proceso productivo o búsqueda de financiamiento y certificaciones, aunque siempre laboran. La CP4 experimenta una situación similar, el presidente se capacitó informalmente en la actividad productiva y consiguió maquilar para una empresa privada, sin embargo, los demás socios no han realizado otras propuestas relevantes, aunque sí participan en el trabajo diario. En ambos casos esto muestra un predominio de socios seguidores (Romero, 2018) y una posible relación de complicidad entre los socios líderes y seguidores debido a que el trabajo de ambos mantiene las condiciones de "estabilidad laboral" (véase la red 1) propio de la modernidad sólida, pero no de la ESS. Respecto a la relación comunidad e individuo de la ESS en las cooperativas analizadas falta la conexión con otras experiencias colectivas y democráticas de economía alternativa para satisfacer las necesidades comunitarias (Coraggio, 2009).

\subsection{La toma democrática de decisiones mediante la Asamblea General}

Las organizaciones de la ESS y las cooperativas tienen como valores y principios característicos la autogestión, control democrático y autonomía. Si bien es atribución de los socios en Asamblea General planear y elegir democráticamente mediante la deliberación (Utting, Van Dijk \& Matheï, 2014), esto depende de la voluntad y el incentivo de participación de los socios en términos de erigirse como nuevos socios líderes de acuerdo con la teoría del liderazgo compartido (Romero, 2018).

2. Para conocer más detalles sobre el éxito de las ocho cooperativas analizadas véase Luvián, Rosas \& Ramírez (2019). 


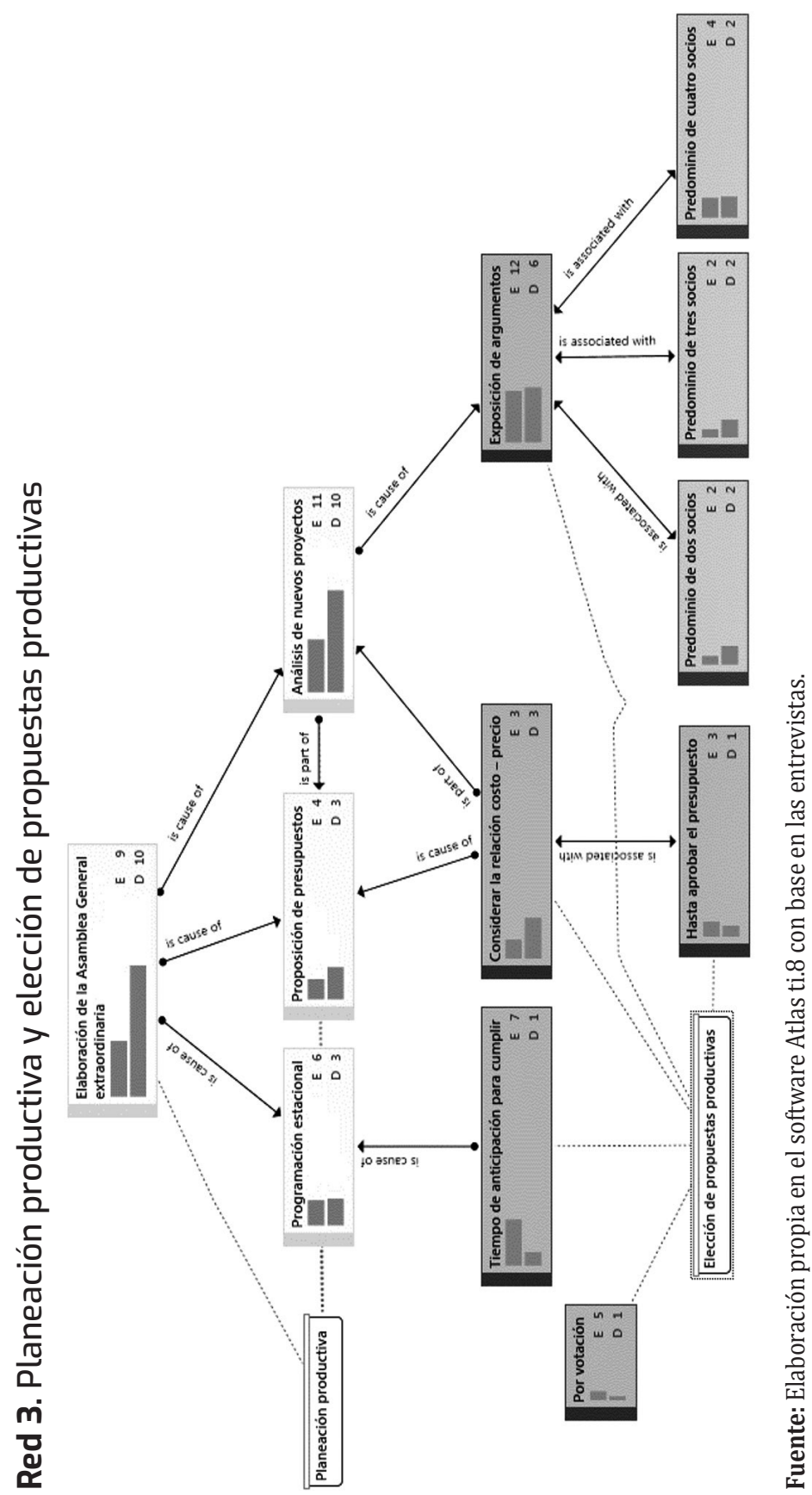


A diferencia de la relación capital-trabajo de la modernidad sólida, el trabajo emancipado cooperativista de la ESS recupera la creatividad intelectual en las asambleas, el control de los medios de producción y el protagonismo para el desarrollo del ser humano (Arruda, 2010) inexistente en el trabajo asalariado apropiado por los capitalistas, monótono y vigilado (Pérez, 2019). En las ocho cooperativas los socios practican el principio de control democrático mediante la "planeación productiva" con la "elaboración de la Asamblea General extraordinaria" o un equivalente (véase la red 3) en ella realizan el "análisis de nuevos proyectos" (aumento de la producción, venta a empresas y obtención de recursos financieros). Cinco cooperativas (CA1, CA2, CP1, CP2 y CP3) usan la Asamblea para la "programación estacional" de la producción y cuatro (CP1, CA1, CA2 y CS2) para la "proposición de presupuestos" (véase la red 3).

El paso siguiente de la planeación de acuerdo con Utting, Van Dijk \& Matheï (2014) es la "elección de propuestas productivas" mediante deliberación, en las ocho cooperativas mencionaron que prefieren llegar al consenso con la "exposición de argumentos"; esta subcategoría se ha categorizado de acuerdo a la teoría del liderazgo compartido el "predominio de socios [líderes]" en la Asamblea: dos en las cooperativas CA2, CP4 y CS1, tres en CP3 y CS2 y cuatro en CA1, CP1 y CP2 (véase la tabla 2 y red 3). No hay inactividad de los socios seguidores, porque legitiman las decisiones con su trabajo; pero de acuerdo con Romero (2018) y Bauman (2017) reproducen un rol pasivo al seguir las propuestas de los líderes, no acorde a la ESS pese a que contribuyen a la estabilidad laboral (véase la red 1). Sólo en tres casos (CA2, CP2 y CS1) escogen "por votación" cooperativista (véase la red 3). De acuerdo a la ESS los socios planean y eligen para proteger su fuente de trabajo de manera colectiva y decidir el uso de los excedentes generados, por lo que otras consideraciones para la elección de propuestas son: en cinco cooperativas (CA1, CA2, CP2, CP3 y CP4) el "tiempo de anticipación para cumplir", en tres cooperativas (CA1, CA2 y CS2) "hasta aprobar el presupuesto" y "considerar la relación costo-precio" y en CA1, CP1 y CS2 al desarrollar un proyecto con riesgos monetarios o de comercialización (véase la red 3).

\subsection{La responsabilidad en las cooperativas urbanas analizadas}

Las cooperativas respectivamente en 2018 tenían cinco, siete, diez y once años de operación (véase la tabla 1), por lo tanto, los socios de cada cooperativa inevitablemente han tenido que hacerse responsables colectivamente de los resultados de las elecciones tomadas en Asamblea General. La comunidad conlleva responsabilidades, contrario al individualismo que es un estado de irresponsabilidad o vínculos de corto plazo (Núñez, 2017). 


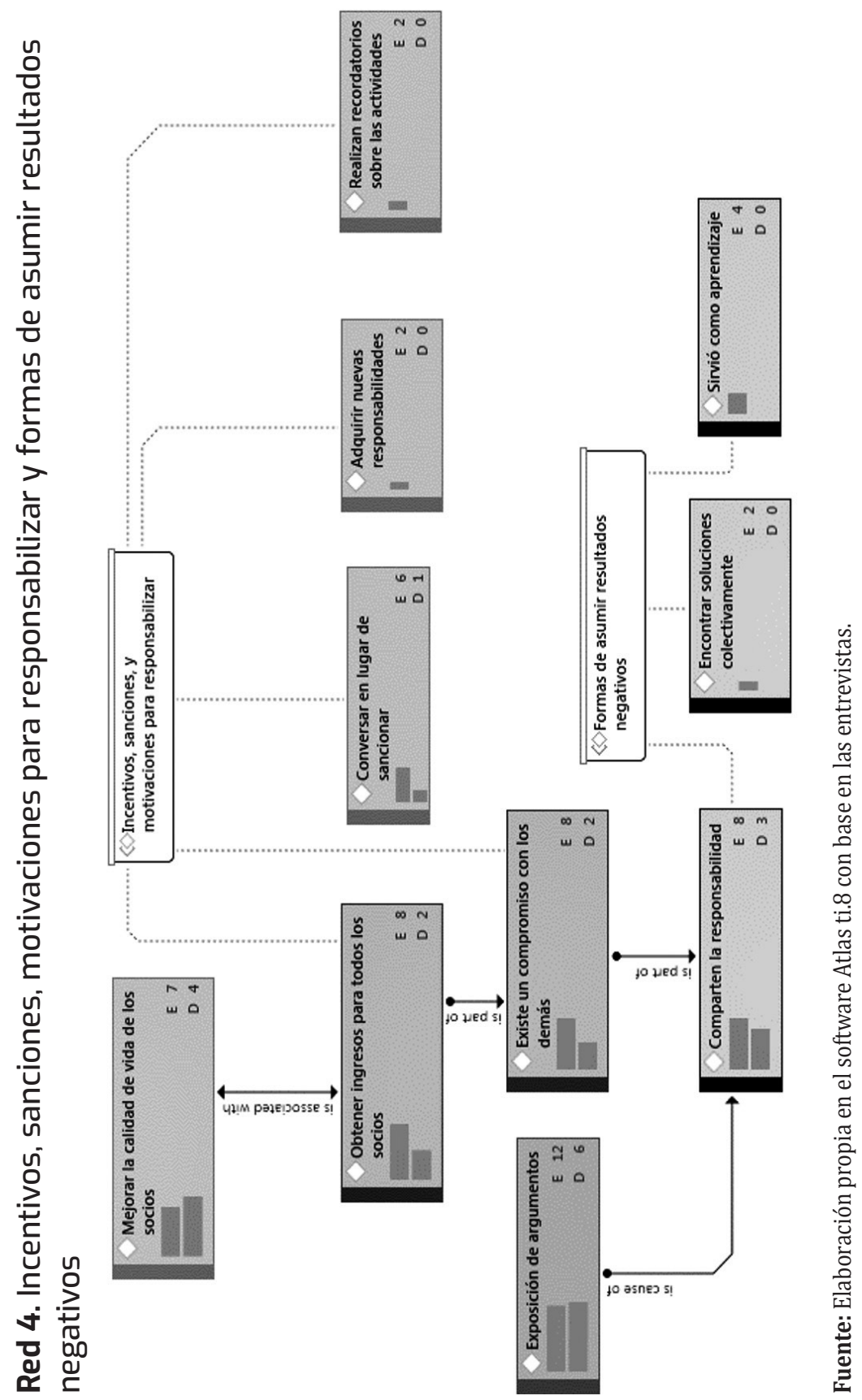


Si bien el liderazgo compartido depende de los líderes para promover una actitud democrática en los seguidores, Sánchez (et al., 2014) señala que la motivación está por encima del liderazgo en la ESS. En las ocho cooperativas analizadas los socios no desempeñan por incentivos monetarios las acciones elegidas en la Asamblea General, sino, por las motivaciones que provienen de la satisfacción de necesidades externas al sujeto, de la solidaridad o el servicio a los demás correspondientes a una lógica distinta a la individualista (Sánchez et al., 2014). Siete entrevistados (excepto la CA2) mencionaron que "existe un compromiso con los demás", como en la modernidad sólida la cooperativa fomenta la comunidad mediante la estabilidad, lealtad, seguridad, ética y progreso (Leira, 2017; González, 2007) lo que contribuye en siete cooperativas (excepto la CA1) a "obtener ingresos para todos los socios" (véase la red 4). Lo anterior co-ocurre en seis cooperativas (excepto la CA2 y CP4) y deriva en "mejorar la calidad de vida de los socios", el trabajo genera logros acumulativos (Sennett, 2010) en la vivienda, infraestructura de la cooperativa, satisfactores y vehículos que facilitan su actividad productiva (véase la red 4). También coincide con el trabajo emancipado que convierte al sujeto en protagonista (Arruda, 2010; Valverde, 2014) y recupera el sentido de la vida mediante la satisfacción y el goce de los excedentes del trabajo (Arruda, 2010). Dos socios (CA1 y CP3) mencionaron que otro incentivo para acatar las elecciones de la Asamblea General era "adquirir nuevas responsabilidades" al mostrar sus capacidades (véase la red 4) el trabajo en estos casos genera orgullo y reconocimiento, coincide con lo planteado por Sánchez (et al., 2014) en que hay motivos intrínsecos provenientes de la satisfacción personal para trascender. Dos organizaciones para motivar la responsabilidad de los miembros (CA2 y CS2) adicionalmente "realizan recordatorios sobre las actividades" tanto digitales como escritos (véase la red 4).

Respecto a los resultados de las propuestas elegidas en la Asamblea General, se preguntó sobre las "formas de asumir resultados negativos" para tratar de evidenciar el protagonismo de los líderes, sin embargo, los socios no consideraron que existiese esta situación. En las ocho cooperativas los miembros "comparten la responsabilidad" del resultado de las decisiones elegidas, subcategoría enlazada a la "exposición de argumentos" en la Asamblea (véase la red 4). No se señalan culpables debido a que todos ejecutan el trabajo, a pesar de haber algunos socios más involucrados en la planeación, esto lleva a que en tres cooperativas (CA2, CP4 y CS1) haya una aceptación del estancamiento del liderazgo compartido. Como en la modernidad sólida la confianza proviene de la identidad, vínculos afectivos, relaciones sociales y en este caso familiares (Salazar, 2007). En seis cooperativas (CA1, CP1, CP3, CP4, CS1 y CS2) los socios prefieren "conversar en lugar de sancionar" para solucionar problemas (véase la red 4). En tres cooperativas (CA1, CP2 y CS2) el resultado negativo "sirvió como aprendizaje" de algo que no debe repetirse cuando implica importantes pérdidas económicas (véase la red 4). En dos organizaciones (CP3 y CS1) se mencionó que si bien comparten la responsabilidad tratan de "encontrar soluciones colectivamente" (véase la red 4). Sólo en dos casos (CA2 y CP2) aplican sanciones monetarias menores cuando la praxis conlleva pérdidas monetarias. En las subcategorías anteriores no se aprecia la competencia o el individualismo como medio de defensa (Leira, 2017) sino la cooperación de los socios para generar una mayor o menor estabilidad que proporciona seguridad. 


\section{Conclusiones}

En este artículo se mostró, por un lado, que los socios de las pequeñas cooperativas familiares analizadas de la Ciudad de México desarrollaron condiciones laborales de estabilidad semejantes a las que tenían los trabajadores en la modernidad sólida. Y, por otro lado, esas condiciones de estabilidad no se quedan únicamente ahí, sino que presentan características del trabajo emancipado consistentes con la ESS (Arruda, 2010). El trabajo emancipado en la ESS se enfoca al desarrollo del ser humano mediante la satisfacción de las necesidades materiales y del espíritu de la comunidad y la persona, implica una apropiación del trabajo y el goce social de sus frutos. Esto es relevante por ubicarse en un contexto en el que predomina una subjetividad neoliberal de irresponsabilidad y extremo individualismo que puede llevar al abandono de las formas democráticas y de participación en las cooperativas.

En los casos presentados la estabilidad está vinculada a: la seguridad laboral, planificar la vida a largo plazo y la comunidad urbana, de acuerdo con la relación capital-trabajo, espacio-tiempo y comunidad e individuo de la modernidad sólida y ESS. Las condiciones de estabilidad son resultado de: rendimientos fijos (generados sin dificultad), lugar de trabajo estable (permite vínculos afectivos e identidad), horarios fijos de trabajo (genera previsibilidad) y ahorro destinado a gastos médicos mediante el fondo de previsión social (la seguridad permite soluciones futuras). En términos generales las cooperativas estudiadas tienen estas características, en detrimento cuando se presenta una menor participación democrática y planeación. Sin embargo, la creación de jubilaciones es un aspecto que tendría que ser más atendido en las cooperativas.

El trabajo emancipado en las cooperativas analizadas es resultado de un régimen de apropiación y disfrute colectivo del excedente, basado en el control colectivo de los medios de producción, apoyado en una estructura legal, principios, objetivos y valores, que permiten en Asamblea General la gestión y toma democrática de decisiones. En estas cooperativas la relación comunidad e individuo al igual que en la ESS privilegia la comunidad, mediante la protección del trabajo al ejercer la creatividad intelectual y el compromiso colectivo para garantizar la actividad productiva (producción, ventas y obtención de recursos financieros). La participación y la democracia permiten el desarrollo de las condiciones de seguridad laboral y el uso de los excedentes.

El trabajo emancipado en la gestión de las cooperativas analizadas parte de un compromiso colectivo y personal, tal como se plantea en la ESS la motivación está por encima del liderazgo. En las entrevistas se mostró que el incentivo de los socios para llegar a acuerdos en la Asamblea no es monetario, predominó el compromiso y la responsabilidad con los demás; se busca obtener ingresos para la estabilidad de todos los socios y mejorar la calidad de vida al obtener una satisfacción y goce de los excedentes. Si bien existe un incentivo personal basado en el reconocimiento y la satisfacción personal este no predomina. La confianza es un elemento central de la gestión y se fomenta al compartir las responsabilidades, las sanciones son menores y hay pocos recordatorios para motivar la responsabilidad, puesto que la estabilidad posibilita el compromiso. Los resultados negativos no tienen afectaciones a la confianza, normalmente 
se reflexiona en lugar de sancionar y se toman como aprendizaje para mantener la estabilidad económica al no repetir pérdidas económicas. La participación democrática para mantener la estabilidad se expresa principalmente en las actividades del Consejo de Administración y menormente en el Consejo de Vigilancia por los vínculos familiares y la confianza creada.

Contribución de cada autor/a: Contribución paritaria LUVIÁN-REYES, G. \& ROSAS-BAÑOS, M.

Financiación: Estudio financiado con recursos propios de los investigadores.

\section{Bibliografía}

ARRUDA, M. (2005): Humanizar lo infrahumano: la formación del ser humano integral: homo evolutivo, praxis y economía solidaria, Barcelona, España: Icaria Editorial.

ARRUDA, M. (2010): "La socioeconomía solidaria y el trabajo emancipado". En: Hacer real lo posible. La formación del ser humano integral: economía solidaria, desarrollo y el futuro del trabajo, Barcelona, España: Icaria Editorial.

BALCÁZAR, C. (2019): “Neoliberalismo, migraciones y precarización laboral en México." Migración, cultura y estudios de género desde la perspectiva regional, Ciudad de México. México. Universidad Nacional Autónoma de México y Asociación Mexicana de Ciencias para el Desarrollo Regional A.C, Coeditores. Disponible en: http://ru.iiec.unam.mx/4787/.

BAUMAN, Z. (2003): Modernidad líquida. México: Fondo de Cultura Económica.

BAUMAN, Z. (2017): Retrotopía. Barcelona, España: Ediciones Paidós.

BÉJAR, H. (2000): "Reseña de "La corrosión del carácter" de Richard Sennett". REIS, Revista Española de Investigaciones Sociológicas, 91, 189-191. Disponible en: https://www.redalyc.org/pdf/997/99717878009.pdf

BIALAKOWSKY, A. \& HERMO, J. (2014): “Repensar la sociología del trabajo desde el Sur Global. Nuevos y viejos desafíos para comprender los procesos sociales de trabajo en el capitalismo globalizado", Revista Mexicana de Ciencias Políticas y Sociales, Universidad Nacional Autónoma de México Nueva Época, 60(224), 45-70, DOI: 10.1016/S0185-1918(15)30003-9.

CAMILLETTI, A., GUIDINI, J., HERRERA, A., RODRÍGUEZ, M., MARTÍ, J., SORÍA, C., TORRELLI, M. \& SILVEIRA, M. (2005): "Cooperativas de trabajo en el Cono Sur. Matrices de surgimiento y modelos de gestión", Revista Unircoop, 3(1), 32-56. Disponible en: https://core.ac.uk/download/pdf/76482767.pdf 
CÁRDENAS, J. (2015): “Las características jurídicas del neoliberalismo”, Cuestiones constitucionales, 32, 3-44, D0I: 10.1016/j.rmdc.2016.03.001.

CASADO, R. (2018): "The 'hero-leader': a case of leadership in Brazil", Leadership \& organization development journal, 39(4), 495-506, D0I:10.1108/LODJ-05-2017-0145.

CORAGGIO, J.L. (2009): "Los caminos de la economía social y solidaria. Presentación del dossier", Iconos. Revista de Ciencias Sociales, 33, 29-38. Disponible en: https://revistas.flacsoandes.edu.ec/iconos/article/download/314/306/

DUMÉNIL, G. \& LÉVY, D. (2011): “Una teoría marxista del neoliberalismo”. Displonible en: https://marxismocritico.com/2011/10/24/una-teoria-marxista-del-neoliberalismo/

ERRASTI, A., BRETOS, I. \& NUNEZ, A. (2017): "The Viability of Cooperatives: The Fall of the Mondragon Cooperative Fagor", Review of Radical Political Economics, 49, 181-197, DOI: $10.1177 / 0486613416666533$

FERNÁNDEZ, L. (2006): “Cómo analizar datos cualitativos?”, Butlletí LaRecerca, 7, 1-13. Disponible en:

https://ebevidencia.com/wp-content/uploads/2014/12/analisis-datos-cualitativos.pdf

FONTENEAU, B., NEAMTAM, N., WANYAMA, F., PEREIRA, L. \& DE POORTER, M. (2010): “Economía social y solidaria: construyendo un entendimiento común. Documento de trabajo", Centro Internacional de Formación de la Organización Internacional del Trabajo. Disponible en: https://www.ilo.org/wcmsp5/groups/public/---ed_emp/---emp_ent/---coop/documents/ publication/wcms_546400.pdf

GEILFUS, F. (2002): 80 Herramientas para el Desarrollo Participativo: diagnóstico, planificación, monitoreo, evaluación, San José, Costa Rica: Instituto Interamericano de Cooperación para la Agricultura.

GONZÁLEZ, K., MORTIGO, A. \& BERDUGO, N. (2014): "La configuración de perfiles profesionales en la educación superior y las implicaciones en el currículo", Revista Científica General José María Córdova, 12(14), 165-182. Disponible en: http://www.scielo.org.co/pdf/recig/v12n14/ v12n14a10.pdf

GONZÁLEZ, N. (2007): “Bauman, identidad y comunidad”, Espiral, 14(40), 179-198. Recuperado de: https://www.redalyc.org/pdf/138/13804007.pdf

GONZÁLEZ, L. \& SAN BARTOLOMÉ, J.C. (2009): Balance Social Cooperativo: Una construcción en construcción. Ética, compromiso y transparencia en la gestión cooperativa, Buenos Aires, Argentina: Confederación Cooperativa de la República Argentina (COOPERAR).

HERNÁNDEZ, J. (2016): “La modernidad líquida”, Revista Política y Cultura, 45, 279-282. Disponible en: https://www.redalyc.org/pdf/267/26745428014.pdf 
IBARRA, D. (2012): “Mercado de trabajo y protección social: Con referencia especial a México", Economía UNAM, 9(25), 3-13. Disponible en:

http://www.scielo.org.mx/scielo.php?script=sci_arttext\&pid=S1665-952X2012000100001.

LGSC (1994): Ley General de Sociedades Cooperativas. Diario Oficial de la Federación. Congreso de la Unión, México. Última reforma publicada 13-08-2009.

LEE, L.M. (2011): “Modernity, Solidity and Agency: Liquidity Reconsidered”, Sociology, 45(4), 650-664, DOI:10.1177/0038038511406582

LEE, L.M. (2014): “Modernity and crowds: Solidity, liquidity and order", Distinktion: Journal of Social Theory, 15(3), 296-308. D0I:10.1080/1600910X.2014.942225.

LEIRA, G. (2017): "En torno a Zygmunt Bauman: retrotopía. Ensayo y reflexiones", Telos: Revista iberoamericana de estudios utilitaristas, 2, 101-117, DOI: https://doi.org/10.15304/t.21.2.4983.

LUVIÁN, G., ROSAS, M. \& RAMÍREZ, E.Y. (2019): “Pequeñas cooperativas de producción exitosas de la Ciudad de México: perspectivas y estrategias de los socios en la modernidad capitalista", Otra Economía, 12(22), 42-65. Disponible en:

https://www.revistaotraeconomia.org/index.php/otraeconomia/article/view/14795.

MADRID, F. \& CERÓN, H. (2012): Evaluación de desempeño de los destinos turísticos en el marco de los Convenios de Coordinación en materia de Reasignación de Recursos (CCRR), Ciudad de México. Secretaría de Turismo. Disponible en:

http://www.sectur.gob.mx/wp-content/uploads/2014/09/IDT_DoctoMaestro_12.pdf.

MARQUES, J.S. (2014): "Social and Solidarity Economy: Between emancipation and reproduction", Occasional Paper: Potential and Limits of Social and Solidarity Economy, Geneva, 2, 22, United Nations Research Institute for Social Development (UNRISD). Disponible en: http:// www.unrisd.org/unrisd/website/document.nsf/(httpPublications)/5A8827ACCEA7CF51C1257CA2005BD240?0penDocument.

MARTíNEZ, M. (2001): "Uso del Programa Computacional Atlas.ti de Thomas Mühr (Univ. de Berlín) en la estructuración teórica de "datos" cualitativos", Revista Argos, 34, 139-156. Disponible en: http://prof.usb.ve/miguelm/estructuracionteorica\%203.html

MARTÍNEZ, J.G. (2006): El Estado mexicano de bienestar, Distrito Federal, México: Miguel Ángel Porrúa - H. Cámara de Diputados.

MEITTA, G., CAVINA, R. \& FRANCO, A. (1966): Razões de Êxito Econômico em Cooperativas de Venda na Região de Rezende, Bogotá, Colombia: IICA - CIRA.

MUÑOZ, J. \& SAHAGÚN, M. (2017): Hacer análisis cualitativo con ATLAS.ti 7. Manual de uso. Disponible en: http://manualatlas.psicologiasocial.eu/ 
MUSACCHIO, A. (2020): “Neoliberalismo, inserción internacional y financiarización: una comparación entre Argentina y Portugal”, Problemas del Desarrollo Revista Latinoamericana de Economía, 51(201), 155-178. D0I.ORG/10.22201/IIEC.20078951E.2020.201.69442.

NÚÑEZ, C.J. (2017): "Apuntes para administración solidaria: una perspectiva desde la ecología política y la línea abismal”, REDPOL. Estado, Gobierno y Políticas Públicas, 16, 39-50.

ODRIOZOLA, S. \& COLINA, H. (2015): "La relación capital-trabajo: ¿cuánto de ayer, cuánto de hoy?", Economía y Desarrollo, 155(2), 6-17. Disponible en: http://scielo.sld.cu/scielo.php?script=sci_arttext\&pid=S0252-85842015000300001\&lng=es\&tlng=es.

ORDÓÑEZ, B.G. (2012): “El régimen de bienestar en los gobiernos de la alternancia en México”, Polis, 8(1), 213-240.

PORTILLA, 0.C. (2005): "Política social: del Estado de Bienestar al Estado Neoliberal, las fallas recurrentes en su aplicación", Espacios Públicos, 8(16), 100-116. Disponible en: https://www.redalyc.org/articulo.oa?id=67681607

PÉREZ, J.P. (2019): "El trabajo: la transición de la modernidad sólida a la líquida. Una aproximación al pensamiento sociológico de Zygmunt Bauman", SCIO, Revista de Filosofía, 17, 79-105.

RAMÍREZ, E.Y. (Coord.) (2013): El cooperativismo y la economía social y solidaria; alternativas para el bienestar de la sociedad. Manual socioeducativo, Distrito Federal, México: Ministerio Federal de Cooperación Económica y Desarrollo.

RAZETO, L. (1993): De la economía popular a la economía de solidaridad: un proyecto de desarrollo alternativo, Santiago, Chile: Programa de Economía del Trabajo.

ROMERO, M. (2018): “Cooperativas de trabajo y liderazgo compartido", Revista Indelcoop, 224, 64-79. Disponible en: https://www.idelcoop.org.ar/sites/www.idelcoop.org.ar/files/revista/ articulos/pdf/224_64-79_reflexiones.pdf.

SALAZAR, L.M. (2007): "Bauman: algunos debates en torno a la modernidad". Documentos de investigación del Colegio Mexiquense, A.C. 1-16 Disponible en: https://www.researchgate. net/publication/319269489_Bauman_algunos_debates_en_torno_a_la_modernidad.

SÁNCHEZ, M.J. (2001): Micro, pequeña y mediana empresa: estudios de casos de éxito. Cooperativa de Servicios Múltiples de Procesamiento de la Harina, INC. (COOPHARINA), Santo Domingo, República Dominicana: Instituto Tecnológico de Santo Domingo.

SÁNCHEZ, S.E., VACA, I.P., PADILLA, J.P. \& QUEZADA, C.R. (2014): “Teorías de liderazgo contemporáneo: análisis de la dinámica relacional”, Revista OIKOS, 18(37), 41-61. Disponible en: https://dialnet.unirioja.es/servlet/articulo?codigo $=6025782$. 
SENNETT, R. (2010): La corrosión del carácter. Las consecuencias personales del trabajo en el nuevo capitalismo, Barcelona, España: Editorial Anagrama.

ULLOA, 0. (2017): "Reforma de pensiones en México: diseño, promesas y evidencias", El Cotidiano, 204, 7-28. Disponible en: https://www.redalyc.org/articulo.oa?id=325/32553151002.

UTTING, P., VAN DIJK, N. \& MATHEÏ, M.A. (2014): "Social and Solidarity Economy Is There a New Economy in the Making?", Potential and Limits of Social and Solidarity Economy, 10, 5-17, United Nations Research Institute for Social Development (UNRISD), Geneva. Disponible en: http://www.unrisd.org/unrisd/website/document.nsf/(httpPublications)/AD29696D41CE69C3C1257D460033C267?0penDocument.

VALVERDE, F.J. (2014): "Persona o individuo en el (neo)liberalismo: algunos fundamentos ideológicos", Pensamiento actual, 14(22), 29-41. Disponible en:

https://dialnet.unirioja.es/servlet/articulo?codigo $=5821494$.

VARGUILLAS, C. (2006): "El uso de atlas.ti y la creatividad del investigador en el análisis cualitativo de contenido upel", Revista de Educación, 12, 73-87. Disponible en: https://www.redalyc.org/pdf/761/76109905.pdf.

VÁZQUEZ, S.J. (2005): “Neoliberalismo y Estado benefactor. El caso mexicano”, Aportes, 10(30), 51-76.

VERSCHUUR (Coord.) (2018): "Solidarity Practices and the Formation of Political Subjects and Actions for Change", Feminist Analysis of Social and Solidarity Economy Practices: Views from Latin America and India. 1-5, United Nations Research Institute for Social Development (UNRISD), Geneva. Disponible en: https://www.unrisd.org/unrisd/website/document.nsf/(httpPublications)/0E53B5F704C9D957C12582F2003A6793?0penDocument. 